\title{
The Way of Gambling: Sources of Government Revenue or Disaster of The Public Sector
}

\author{
Worachet Tho-un ${ }^{1}$, Somchai Saenphumi². \\ ${ }^{1}$ Mahamakut Buddhist University, ${ }^{2}$ Mahamakut Buddhist University. \\ Email: ${ }^{1}$ worachet.th@mbu.ac.th, ${ }^{2}$ Somchai.sa@mbu.ac.th.
}

\begin{abstract}
This article would like to reflect the history of the Thai gambling industry. The nature of gambling that is hidden in tradition, opinion of Thai society towards gambling. Moreover, the effects of gambling that the state allows and does not allow through literature, law, Buddhist principles, the King's philosophy and the theoretical concept of gambling, and the theoretical concept of gambling.

The results of the synthesis of the data showed that gambling has been in conjunction with Thai society for a long time. The context and process of gambling in Thai society can take many forms. It will depend on the context of the environment, the law, and the government, etc. Their views and attitudes towards gambling can be divided into two groups: the one that sees gambling as a pleasure. It has created a social space to legitimize gambling in various forms, such as gambling for gambling. The hidden gambling tradition gambling of the types permitted and prohibited by the government, etc. Furthermore, the second group viewed gambling as a danger to society. It is a terrible thing that the state must restrict it from society. This concept is primarily connected and related to religious and legal principles.

From the information found, I believe that gambling is a huge source of income for the government, even though the state knows that it is mescaline. But cannot cancel the business, that is, the deadly poison or the public's silent threat that is submitted to the government.
\end{abstract}

Keywords

Way of Gambling, Sources of Government Revenue, Disaster of The Public Sector.

Article Received: 10 August 2020, Revised: 25 October 2020, Accepted: 18 November 2020

\section{Introduction}

It is said that in the history of the human world has been playing gambling continuously and for a long time until now. By far, the earliest gambling is dice gambling or throwing dice in a competition. By playing a game called "Astragali" takes place in the Egyptian era of 3,500 years BC. Subsequently, gambling models have been developed that are different according to the era and according to the popularity of people of different races. [1] For Thailand, gambling is a problem that has been long coupled with Thai society. Because Thai people have fun-loving habits and a popular gambling practice. Also, gambling has penetrated groups of people of all levels, whether rich or poor, often enjoy a comprehensive variety of gambling forms. Whether it is playing cards, underground lottery betting, or even online gambling in various forms, which is becoming popular today. [2]

In the context of Thai society with a diversity of sexes, occupations, qualifications, maturity, and lifestyles Inevitably, there will be different ways of thinking, attitude, and behavior in the context of something, such as the current opinion of gambling. Some people's views on gambling justify that "People who gamble Not a bad person If it is for fun without any disparities involved, "it can be seen that this concept has a positive effect on gambling. When this thinking happened, it was distributed among many, making many people unaware or invisible to various forms of social dangers. That will follow, which is the cause of gambling. When considering the types of gambling played in the past year 2019, it was found that Thais preferred to play four types of gambling, namely (1) Government Lottery, which is most popular to play 22.749 million people (2) underground lottery 17.737 million people (3) gambling on cards of 4.446 million people and (4) betting on football predictions of 3.464 million people. As for gambling addiction behaviors, it was found that 17.20 percent admitted that they were addicted to gambling, while the other 14.10 percent were unsure if they were addicted to gambling or not. When calculating the estimate According to the population database aged 15 years and over, when considering the database compiled by the civil registration statistical system, the Department of Provincial Administration, Ministry of Interior for the year 2019, some gamblers admit that they are addicted to gambling. Total of 5,230 million people, while there are 4,291 million gamblers who are unsure whether or not. [3]

Gambling is a social phenomenon that has existed since prehistoric times and continues to date. In Thai society, we often see gambling in general. This is because gamblers have various easily accessible ways of gambling and are integrated into all levels of society. The relationship of gambling lies in the Thai way of life, both in the economic, social, and cultural systems. Temple events, annual events, and funerals, etc. Some types of gambling have youth in the community get involved in gambling to monitor parents into community areas that are open for gambling. The situation reflected youth in the midst of an environment and conditions that would easily influence youth into the circle of gamblers for the future. [4]

The villagers' views on gambling are both positive and negative. Villagers with a positive view commented that "One part of the community gambling is linked to a way of life. Ancestral cultures and traditions such as cockfighting are expressions of fighting and not giving up. In addition, gambling is a sport and recreation that can relieve distress, exchange, and conversation among people in the community, and help some people earn income from the 
community gambling activities, for example Food-to-order trade Instant food alcoholic beverages and other facilities etc. " The group with an opposing view that has commented that Gambling is a punishment. A way of decay and should be avoided because immorality, tradition, and illegal are things that infuse people. Often gamblers or their network of gamblers refer to tradition and culture as an excuse for gambling. They were creating interests for themselves and their companions as a hidden tool behind them, which is backed by capitalists and law enforcement authorities." Therefore, if considered objectively during the argument, gambling has both you and the penalty, which is like a twoedged sword.

\section{The Concept Of Gambling}

From the study of the social criticism of gambling in the past, there are often many people who like to critique religious principles on "Is gambling ethical or not?" One of the pieces of evidence found in Buddhist literature shows that the Buddha does not allow monks to gamble. However, it did not apply this law to the public and reminded me of the six behaviors that only cause deterioration in people's lives. This consists of the Regular drinking of alcohol, Nightlife, Playboy, Gambler, Gangster, and Bummer. On this issue, I would like to present the concept of gambling into four issues: 1 . The study of gambling in the past of society through the perspective of Thai literature; 2 . The current situation of gambling in Thai society 3. Gambling in the online system, and 4. Causes of gambling as follows.

\section{A study of gambling in the past of society through the perspective of Thai literature.}

From the study of gambling in the past in Thai society through a literary perspective, it is found that gambling is prohibited. It appears that both laws and morals prohibit people from engaging in and gambling. However, despite the religious law and doctrine, which prohibits gambling much, gambling still appears in Thai society without any signs of disappearing. Besides, there are still more techniques and methods of gambling. When looking at Thai literature from the Sukhothai period until the reign of King Rama VI, it was found that there was a large amount of literature on gambling on various issues. Historical evidence suggests that gambling first originated in China and then spread to other countries. In India, there is evidence that when the modern era, The Lord Buddha has enacted the punishment of gambling in the fourth practice of Practice, "Gambling is a punishment. It is a way of deterioration." The authors view that if you look at the data, it shows that the source of the civilized day out, namely China and India, has been around for gambling.

From searching for literature from the Sukhothai period, there is no clear information on gambling in Sukhothai society. There is only evidence that the poet has described gambling in many literary subjects, such as the wisdom of the chiang mai monk wrote around 2000-2200 with a total of 50 literary inscriptions in Pali and is a style of writing that imitates the literature written by the Lankan monks. [5] However, in the Thonburi era, King Taksin the Great Instead, the soldiers were allowed to gamble after the war was over, and the public was allowed to gamble on public holidays. (the important day of the nation) without breaking the law and breaking the law of religion.

The literature about Adonis, which was written by King Rama 1, summarizing the issue that "Animals are brought to fights, and there are different forms of gambling. Cheer for fun "and the law enacted three emblems (3 symbols) that appear gambling. "Government officials and people do not comply with religious ordinances. Brought to turn to gambling and drinking most of the alcohol. And there is a punishment for the violators, which is to whip wicker Tattooed gambling pictures on the face And dismissed from the government immediately without parole " [6]

The era of King Rama III had a severe economic crisis. People hid the money under the land Money is not used to spend in the market system, so economic advisors (Chinese) proposed a policy to stimulate the economy, namely opening a casino and allowing people to buy government lottery. [7] Later, in King Rama VI's reign, the public was strictly prohibited from gambling on 1st April 1916 but still found illegal gambling in various places. [8]

\section{Gambling patterns in the present situation of Thai society.}

Under section 4 of the Gambling Act, B.E. 2478, Gambling is divided into two categories: absolute prohibited betting and licensed betting. Explain that even though gambling can have an impact on the player and the social context. The government or rulers are also allowed to allow people to gamble. [9] The authors view such methods and processes that it is evident that gambling is an income-generating matter, such as the government lottery, which generates vast incomes and expenditures to huge fortune-telling players. Overall, the repeal of the underground lottery crackdown is very sensitive and sensitive to people's feelings in Thai society.

\section{Online gambling.}

In today's world society, the online gambling process has become widely popular both within the country and abroad. For Thailand, online gambling through information technology media in various forms. These are still illegal, and there is no legal process or government policy to deal with this matter. Moreover, there is also a widespread hacking of online gambling. it can be said that "Any gender can play online gambling, age, every day" ever, especially online football betting. Online casinos and online horse racing betting and which tends to expand more and more in Thai society. In foreign countries, online gambling management policies have been established into two approaches: a policy that does not allow online gambling to be a legitimate business such as the United States, Russia, Greece, and Pakistan, and a policy that allows online gambling. Make online gambling a legitimate business such as England, Gibraltar, and Malta. [10]

\section{The Causes of gambling.}

The problems of gambling have come together with people in Thai society with a long history. The context and process 
of gambling in Thai society can take many forms. This will depend on the context of the environment, the law, and the government, etc. Their views and attitudes towards gambling can be divided into two groups: the first group viewed that gambling is the creation of happiness, contentment, and entertainment. It has created a social space to legitimize gambling through various forms, such as gambling for gambling. Hidden gambling traditions government-approved gambling is not guilty and not a bad thing, etc. Moreover, the second group viewed gambling as a punishment. Harmful to society is a bad thing it is against religious doctrine. The government must be restricted from society. This concept is primarily connected and related to religious and legal principles. [11]

\section{Buddhist Concept Of The Punishment Of Gambling.}

Punishment for gambling in Buddhism the Buddha has said six things: 1 . The person who wins gambling creates grief for loser 2. The person who loses gambling will want to get money back 3 . Lose money suddenly 4 . They were breaking the law of the country 5. Lack of trust from colleagues, and 6. No one wants to marry. There are six ways to prevent penalties from gambling: 1. Abstain from drinking alcohol 2. Do not be a nightlife 3. Do not act like a playboy 4. Do not gamble 5. Have good companions, and 6. Diligence. Moreover, the research of Watchara Tanawong (2014) has studied "Measures for the prevention and control of gambling on the Internet" The research results were found that people enjoy gambling on the internet because of the advancement in information technology.

Furthermore, mobile phones can now be used to gamble, which causes gambling on the internet to be damaging in many areas such as the economy, education, religion, culture, etc. Therefore, society must help each other to solve problems. Incidentally, the 1935 Gambling Act applied to gamble on the internet did not work. Because there is a problem in defining gambling on the internet with low penalties and a lack of a clear online gambling regulator. Moreover, the researcher suggested that existing legal measures to suppress offenders, such as tax measures. Measures forbidding financial institutions from engaging in gambling-related transactions territorial liability measures to prosecute gambling websites in foreign countries. It has also suggested policy measures to prevent gambling on the internet, such as social measures. Measures to reduce and stop gambling measures for cooperation between government agencies measures to seek cooperation with the private sector check gambling sites and establish specific gambling regulators. If the aforementioned recommendations are followed, it is expected that internet gambling will be depleted Thai society.

\section{Guideline For Solving Gambling Problems According To The Philosophy Of The King.}

Philosophy of the King is science born of the developer king. Those whose work is based on science and economics principles are rational, educational, experimental, emphasizing education, learning, and participation as a key element by King Rama 9. He started by studying various subjects and began to conduct his experiments in the Dusit
Palace. Then, the results of these experiments were extended to 6 study centers. It has been developed by adapting the experiment results to suit the local environment, lifestyle, and needs of the villagers in each area, because one theory cannot be applied everywhere. It must be deployed accordingly. Therefore, it is the reason why we have to "understand, access, develop" starting from "understand," that is, understand the local environment. How is the wellbeing of the people? What kind of culture is there and then "approached" by mingling with local people? Building trust then began to "develop" to be consistent with that area.

Her Royal Highness Princess Maha Chakri Sirindhorn said in 2011 that "The King's goal of development is 'Sustainable Development' to improve people's livelihoods. Without destroying the environment, people are happy considering geography, religion, race, and socioeconomic background. Although there are various development methods, developers must have love, care, responsibility. Moreover, respect for fellow human beings. Development is related to humanity and is a matter of the mind. The concept of monarchy aims to develop oneself, family, community, society, and country to have a sustainable shield. Earn money honestly, and it can be fine without the need for any income or gambling. The design thinking the King Rama IX's sustainable development consists of a 6-step process.

1. Empathize

"What are you worried about?" What is often asked when visiting citizens clearly shows the importance of local people first. Along with study and understanding, each area's social and geographic conditions reflect sociopathic and anthropological thinking.

2. Define

A solid understanding of the problem must work with the ability to see the relationship. To lead to identifying real needs at this stage, His highness shows an analyst and a systematic way of thinking.

3. Ideate

When identifying the problem with precision, alternative thinking can be done with a method of thinking like a scientist and an innovator that does not block the possibilities. With significant help is knowledge in various fields and further studies. He has already shown that if there is sufficient factor contributing to knowledge and determination, Humans can modify the weather to make it rain.

\section{Prototype}

One of the key elements of the design process is developing a "prototype" for transforming ideas into shape. Both test the initial idea and lead a practical test, and this process requires both technical research. Moreover, the thought of not giving up or it can be said that it is an inventor way of thinking We can see that the main principles of the development project Because the royal initiative is simplicity and reason, it means an opportunity to take the model to can be applied in different areas endlessly enough. 5. Test

When the prototype was obtained, the key to practical implementation is the do-it-yourself approach, which means applying it to a realistic, local environment with flexibility and practical results. Combined with the continuous improvement of the model with new knowledge to achieve real objectives. That is to improve the quality of life and 
well-being of people to be self-sufficient and sustainable. It can say that land of Suvarnabhumi is a land with a monarchy coupled with a long history of the nation. Whenever the nation is in crisis, The King always thinks of solutions to problems to lead the nation to prosperity prosperous with international. King Rama IX said that "the development of the country is necessary must follow the hierarchy. The foundation must first be established, which is the sufficiency of the people using economical methods and equipment, correct according to academic principles. When having a solid, moderately ready, and practical foundation, Therefore, gradually build-up to the prosperity and higher economic status in the next order If focusing only on creating prosperity Raising economic status only quickly without giving action plans consistent with the state of the country and the people. There will be an imbalance in various matters, which can become a hassle and eventually fail" King Rama IX presented the philosophy of sufficiency economy for the first time at the graduation ceremony at Kasetsart University. On Wednesday, 18th July 1974, what did the King see before telling the people. The teachings of King Rama IX or as we call it. "Philosophy of the King," which encompasses royal ideas and philosophy. His royal speech is instruction and admonition to be conscious. Royal duties are principles of working his people. Furthermore, the royal ethics of King Rama IX throughout the past 70 years, which Thai people have embraced as a good example in their behavior. Including the government and civil servants has applied to the administration of state affairs to build a nation and develop the country in a balanced and sustainable manner.

\section{The Method Of Philosophy Of The King.}

King Rama IX adheres to all three administration aspects: understanding, access and development in caring for his people. For that working principle, He applies to people, objects, society, environment, and culture, has depth, and has a royal project or other work that has been clearly illustrated. His focus was on human development, and saying "it must explode inside," that is, to strengthen the people in the communities we develop into to be ready for development. It is not bringing prosperity or people from outside society to the village community that has not yet had the opportunity to prepare. His highness uses the principle of "understanding, accessing, developing," that is, before doing anything, must have an understanding first understand the terrain understand people in various problems both in physical aspects, customs, and culture, etc.

Moreover, during the operation, we will have to make people who we are going to work with or work for him to understand us. Because if we understand him alone without him understanding us, the benefit would not have happened as we expected. Access is the same. When you know, the problem understands and then needs access to lead to action and when accessing it must do, however, make him want to reach us as well. Therefore, communication between the sender and the receiver If the first two things can be accomplished the issue of development will occur because when different parties understand each other. Each other wants to reach each other already. The development will be mutually agreed upon by both the giver and the receiver.
Working holistically and thinking for work. The holistic approach is to look at things born in a complete system; everything has dimensions connected. Look closely at what happened and how to fix it.

\section{The Proceess Of Philosophy Of The King.}

The context and procedures of the philosophy of the King are as follows.

1. Understanding is comprised of 4 sub-Elements:

- Use of available information

- Use of empirical data

- Analysis and research

- Experiment until it actually works

2. Access is made up of 3 sub-Elements:

- Exploding from inside means giving people or communities that go into development or work to adapt to develop oneself. There was a need to develop himself first. It is not something that the government enters into forcing people or communities to do, which will not be sustainable. Therefore, His highness emphasizes people's development to allow people to change themselves first and then develop and change, which is access before development. It does not bring development without the public recognizing or recognizing the importance of development or change. This principle is consistent with the modern academic principles of change leadership and management, as John P. Kotter put it forward: change must make people aware of the urgent need for change. The vision must be communicated so that people can see a clear direction to change.

- Understanding the target group, which is the people, what the people need before they work to understand the suffering, problem, and suffering of the villagers. To find further solutions

- The creation of social intelligence is a vital part of reaching people. If people still lack understanding, they must create social intelligence for them to understand. Use the easiest way to communicate with people to build intelligence. His highness chooses to use a way of speaking that creates wisdom that is appropriate for the audience.

3. Develop a royal initiative for that development; when he understands, approaches, then develops it, his highness has an important principle:

- Self-starting

- Self-reliance

- Able to be a model for disseminating knowledge

His choice of areas where problems and hardships are developed serves as a model for people to see and follow. Even the most problematic areas can still develop well people should be able to follow through, learning from inspirational models for the development of themselves and the nation. Therefore, the method of understanding, access, and development is the monarchy method for sustainable development. And is the rule of the land fairly for the benefit of the people of Thailand truly

King Rama IX is the King who, in addition to the tenets of Dhotsapithrajadhammas, is also the King who is an exemplar in life and work for his people and other countries. Many people saw his intelligence. Moreover, have a great sense of respect and love for His Majesty the King. The concept or working principle of King Rama IX is very interesting that should be applied to the working life very 
much. If anyone wants to follow what you do, you can apply your work principles to be useful as follows.

1. To do anything, one must study the information systematically. To bring that information to be practical, accurate, fast, and on target.

2. To blasting from the inside means that if you do anything, you have to start with the people involved first, you need to build strength from the inside to understand and want to do. Not ordering others to do

3. Solving problems from small spots, you should always look at the overall problem first, and then start working from small points before solving them one by one.

4. Follow the sequence of steps. Begin by doing what is necessary first. Once this is accomplished, we begin to proceed with the next necessary things carefully and carefully.

5. Any development must take into account the topography of that area. Moreover, sociology of personality traits as well as culture Each local tradition is different.

6. Work holistically; use thinking for work. The holistic approach is to look at things born in a complete system; everything has dimensions connected. Look closely at what happened and how to fix it.

7. Not sticking to texts when we do anything; we should work flexibly with that situation and condition. It is not just sticking to academic textbooks that we sometimes need to be consistent with the natural, environmental, social, and psychological contexts.

8. Know how to save, simple, get the most benefit.

9. Make it easy. He invented, modified, improved, and modified the work. The country's development is simple and, most importantly, consistent with the living conditions of the people and the ecosystem as a whole.

10. Participation in his highness gave the public an opportunity for people or officials at all levels have come to express their opinions. acknowledging other people's opinions

11. Must seize common interests. King Rama IX remembers the interests of the public as necessary.

12. One-stop service, focusing on knowledge, love, unity, and cooperation by reducing gaps between related agencies. 13. Solving natural problems with natural resources.

14. Putting the truth in nature and the rules of nature as principles, practices for solving problems and improving unusual conditions into standard systems.

15. To accomplish any task, you must first cultivate your awareness. Value See the benefit of what to do.

16. The principle of King Rama IX towards Thailand's people is "giving" and "sacrifice." It is a good act, the wellbeing of the people.

17. Self-Reliance: To have the strength to sustain life, the next step is to develop people to live in society according to the environment and finally be self-reliant.

18. Making people able to live in a good position first and then expand to have the capacity to progress further.

19. Sufficiency economy: It is a way of living on the middle path to survive and sustain a stable and sustainable existence under globalization and various changes.

20. Honesty. Sincere with each other who are honest and pure. Even with little knowledge would benefit the public more than those who have much knowledge but without honesty and sincerity.
21. Working by happiness.

22. Starting a job or doing something that may not be ready requires patience and determination.

23. To creating harmony and reconciliation in society.

\section{Controversial Issues And Perspectives}

The perspective on gambling has both positive and negative aspects with an optimistic view claiming that part of gambling is linked to a lifestyle inheritance. Culture and traditions of ancestors, such as cockfighting in the governor's history even with the cockfighting sport, taking the state and the people as a bet As for the rocket festival, the people who are higher up will win. by getting the state and the daughters of the governor as a bet. Gambling is an expression of fighting and not giving up. Non-surrender to destiny besides that, gambling is a sport and recreation that can be relaxing. Is a dialogue area for people in the community including the creation of income from gambling in such as food-drink shops. and other facilities etc.

The negative view towards gambling has claimed that "gambling is catastrophic and should be avoided because it is immoral and illegal. For the most part, gamblers or their networks of gamblers often refer to tradition and culture as an excuse to gamble, with the benefit of themselves and their peers being a hidden tool behind them. Always which is backed by capitalists and law enforcement authorities. However, villagers see one of the biggest problems plagued by community gambling in state gambling and government officials' inaction. Mutual benefit between casino owners or gamblers and certain government officials, specific groups, or agencies.

Free gambling is one of the most sensitive public issues for Thai society. Often governments or government leaders have ideas or policies that can be administered for economic benefit or control to reduce society's negative impact. Social reactions, both in the form of support and opposition, will erupt immediately. However, the arguments raised by each side in support of their opinions have never led Thai society to a solid conclusion about gambling. Even though gambling studies in Thailand, especially over the past ten years, have been carried out fairly widely and regularly, such as when there is a world-class soccer event Research center or various opinion survey agencies often come out to reveal analyses or surveys about football betting. These provide financial information such as estimates of the expected turnover limit during the tournament and reflect some social impact dimensions by providing information about groups of people likely to be involved in football gambling, for example.

Several studies also present interesting policy recommendations on the management of gambling. However, the use of the study results, referred to by those who advocate or oppose the legalization of gambling, is only applied following their opinion, such as those who advocate for economic benefits. The Objections will cite social issues (especially those involving children and youth) and suspicion of law enforcement by government officials, for example, making the reasons or excuses raised to support or refuse to gamble. It is a matter related to political, economic, social, and cultural issues in an elaborate manner. It appears in the form of an opinion arising from a personal 
view that chooses to receive only some information rather than an opinion arising from the actual academic thinking.

\section{Conclusion.}

Considering the context of gambling in Thai society from historical traces through literature and law, it can be seen that gambling is against morality, religion, and law. Some state rulers do not allow gambling, and the punishment is strictly prohibited. Some state rulers supported and allowed them to play freely. Some state rulers introduced economic stimulus policies through a gambling system. In other words, gambling is available in most states. A state authority creates gambling to benefit from managing the state or its interests in which the gambler is a prime customer. Nevertheless, if you look at the opposite point of view, gambling has always been the state's monopoly. The effects of gambling on society such as crimes, social perils, prevention, repression and social remedies. It is something that the rulers of the state know well.

Moreover, surprising are some of the state's policies and productivity, such as state-licensed gambling. Suppose asked if the state's governor knew that gambling had severe penalties on the people. Why do the rulers continue to do so? Why can't the state cancel and transcend? Suppose Thai society cannot accept the opening of a casino in the country. In that case, the author proposes that we create an experimental project designated as a casino for foreigners only, by choosing an area far away from the community and built as a comprehensive entertainment center. The state, as a public service manager, may joint venture with private operations. Then study the pros - cons. And then came to do a public hearing Doing so will be informed of the actual facts. Not just an estimate. However, if we allow a casino, the state should also have an organization that manages and educates gambling for Thais, which may be established as a committee in a state agency, such as the casino affairs standards committee. The committee for scrutinizing people who are gambling. Those who will gamble will be checked for history and qualifications first, such as age, income, criminal history, status, etc., to prevent gambling until the bankruptcy and not to think that gambling is for profit.

In addition, the state must protect low-income people or students without income. Not to enter the state-owned gambling circuit In addition to preventing initially, the organization of remedies or counseling from people with gambling addicts because when the state has made gambling all the disadvantages arise, the state becomes the sole responsibility of the state. In short, when the state will provide a casino, it should also manage to maintain the disadvantages of the casino that arise later. In addition to that, one of the most dreadful aspects of state gambling is money laundering. We must organize a system to prevent state gambling from becoming a money laundering ground for illegal businesses. Therefore, the way of gambling is a source of income for the Thai state. Alternatively, is it a terrible disaster that the government has have been mescaline for a long time this answer must be in everyone's mind. The part of agreeing or disagreeing probably only you would be able to understand yourself the most. Besides, religious doctrine, monarchy, law, government policy, public administration, community management, education, family, and self-behavior are the context and factors that are important to the Perspectives and management of gambling in Thai society.

\section{References}

[1] W. Samkoset. Gambling history, life and tears. Retrieved on 10th April 2004, from https://www. libdoc.dpu.ac.th. 2004.

[2] C. Ratchada Pannathikun. "Legal measures related to gambling in Malaysia". Journal of Justice. Vol. 6, no. 3 pp. 3-5. 2013

[3] Center for Gambling Studies Chulalongkorn University Situation, Behavior and Impact Study Report Gambling in Thailand 2019. Center for Gambling Studies Chulalongkorn Report. 2019.

[4] K. Suvicha and B. Cholthida. Situation, Behavior and Impact Study Report Gambling in Thailand 2019. Center for Gambling Studies Chulalongkorn Report. 2019.

[5] Phadhammasitthajarn. Intelligence Node. A memorial ceremony in the cremation ceremony, Wat Phra Singh Woramahawihan, Chiang Mai Province: (3rd edition), Sillapa Bunna Publishing House. P. 36. 2019.

[6] Three seals law., p. 704. 1962.

[7] C. Lohachala. Memorial Cremation Ceremony Police Major General Suwit Sotthitat. Bangkok: Font Relation Printing House. 1981.

[8] S. Plailek. "Gambling in Thai society: literary reflection". Wanwitit Journal, Vol. 4, no. 4 p. 28.2004.

[9] S. Noppawan. Control and definition of gambling. 2020. Retrieved on 15th April 2020, from https://www. thaihealth.or.th.

[10] S. Wongkratanyoo. Theory of participation. Retrieved on 15th April 2020, from https://www. gotoknow.org. 2020.

[11] The Holy Tipitaka, Volume 11, page 202. 